\title{
Supporting parenting to address social inequalities in health: a synthesis of systematic reviews
}

\author{
Annabelle Pierron ${ }^{1 *}$ (D) Laurence Fond-Harmant ${ }^{2}$, Anne Laurent ${ }^{3}$ and François Alla ${ }^{4}$
}

\begin{abstract}
Background: In 2009, the World Health Organization's Commission on Social Determinants of Health set out its recommendations for action, which included establishing equity from early childhood onwards by enabling all children and their mothers to benefit from a comprehensive package of quality programmes. In order to address social inequalities in health, it is recommended that action be taken from early childhood, and actions providing support for parenting are an effective lever in this respect.

The aim of this review of systematic reviews is to analyse, on the one hand, the components and characteristics of effective interventions in parenting support and, on the other, the extent to which the reviews took into account social inequalities in health.

Methods: A total of 796 reviews were selected from peer-reviewed journals published between 2009 and 2016 in French or English. Of these, 21 reviews responding to the AMSTAR and selected ROBIS criteria were retained. These were analysed in relation to the consideration they gave to social inequalities in health according to PRISMA-equity.

Results: The reviews confirmed that parenting support programmes improved infants' sleep, increased mothers' self-esteem and reduced mothers' anger, anxiety and stress levels. The mainly authors noted that the contexts in which the interventions had taken place were described either scantly or not at all, making it difficult to evaluate them. Only half of the reviews had addressed the question of social inequalities in health. In particular, there had been little research conducted on the relational aspect and the social link.

Conclusion: In terms of addressing social inequalities in perinatal health, the approach remains both modest and reductive. Understanding how, for whom and in what conditions interventions operate is one way of optimising their results. Further research is needed to study the interactions between the interventions and their contexts.
\end{abstract}

Keywords: Social determinants of health, Disparity, Perinatology, Parenting, Health promotion, Healthcare disparities, Health status disparities

\section{Background}

The social determinants of health are one of the principal causes of health inequalities, that is the unjust and sizeable discrepancies recorded between social or geographical groups [1-7]. In 2009, the World Health Organization's (WHO) Commission on Social Determinants of Health set out its recommendations for action, which included establishing equity from early childhood onwards by

\footnotetext{
* Correspondence: annabelle.pierron@univ-lorraine.fr

${ }^{1}$ Université de Lorraine, EA4360 APEMAC, Vandoeuvre-lès-Nancy, France

Full list of author information is available at the end of the article
}

enabling all children and their mothers to benefit from a comprehensive package of quality programmes [8].

Early childhood is a key period in the genesis and reproduction of Social Inequalities in Health (SIH). Epigenetic studies and life course epidemiology confirm the link between life circumstances in early childhood and health in adulthood [9-13]. Social inequalities have an effect on health, most notably by creating biological modifications throughout the life course. In particular, development is negatively influenced by antenatal and neonatal stress [14-20]. 
Clearly, the perinatal period is particularly sensitive. Promoting the health of pregnant women and new mothers is therefore essential, and parenting support is one of the principal strategies that can really help [13, 21-23].

Many publications show that parenting support is an effective lever in promoting health in mothers and their newborns, and they are the subject of many reviews. However, have these studies taken into account SIH? The aim of this review of systematic reviews is to analyse, on the one hand, the components and characteristics of effective interventions in parenting support and, on the other, the extent to which the reviews have taken into account $\mathrm{SIH}$.

\section{Methods}

\section{Study procedure}

The screening, eligibility and inclusion stages were conducted and presented according to the Preferred Reporting Items for Systematic Reviews and Meta-Analyses model (PRISMA) [24, 25].

The study population was pregnant women, parents of newborns and newborns (from birth to 3 years old, preschool). The interventions involved promoting perinatal health, and more specifically, programmes and schemes offering parenting support - from the standpoint of obstetrics, paediatrics, psychology, sociology, education and public health, in the broad sense of the term.

The comparators were not relevant to this study. All the results (whether favourable or not) were collated and evaluated according to their effects on SIH, their psychosocial effects and their effects on perceived health. Intervention durations were taken into consideration.

A systematic search was conducted using Cochrane, PubMed and PsycINFO, which are the principal scientific databases in the field of health. The keywords referenced in the MeSH (Medical Subject Heading) were based on perinatal health promotion, $\mathrm{SIH}$, the social determinants of health, parenting support and health programmes relating to parenting support (Table 1). Keywords were selected in collaboration with Céline Aubert, documentalist at the Faculté de Médecine in Nancy.

The search formulas combined the following terms: ((parenting OR parenthood) AND ("support")), ((parenting OR parenthood) AND ("health promotion")), ((children) AND "health promotion" AND parent") OR ((parenting OR parenthood) AND ("health promotion")), ((children) AND "health promotion" AND parent*) OR ((parenting OR parenthood) AND ("equity")), ((parenting AND parenthood) AND (inequit*)), ((parenting AND parenthood) AND "health inequit"), (parenting OR parenthood) AND (social"determinant*)) and (parenting OR parenthood) AND(disparit*)).
Each of the standardised search formulas was reproduced for all the databases, based on titles, abstracts and keywords, for journals published in French or English between January 2009 and September 2016.

The research protocol was written but not published. It is available on request from the authors.

\section{Selection of articles}

The documents retained were all narrative and systematic reviews published in French or English in peer-reviewed journals between 2009 and 2016. The year 2009 was chosen as the start date because it was the year the WHO published its report from the Commission on Social Determinants of Health [8].

Interventions relating to prematurity, a specific pathology or to those concerning school-age children were excluded, as were reviews of reviews. Duplicate articles were also removed. The reason for each individual rejection was given in a note. A pilot study was carried out in May 2016 using a sample of the articles in order to validate the protocol (relevance of the search formula, selection criteria, evaluative consistency of the different team members).

The full texts of the articles selected were subject to a methodical, standardised interpretation responding to each of the AMSTAR (Assessing the Methodological Quality of Systematic Reviews) items [26]. The reviews that did not meet these criteria of methodological quality were excluded.

The selected reviews were all included whether or not their results were favourable so as to exclude the possibility of any bias resulting from selective publication of results. The grey literature and the recommendations published by France's Haute Autorité de Santé and the UK's National Institute for Health and Clinical Excellence were subject to an exploratory study but were not retained for this review since they did not correspond to the study aims. Table 2 shows the PICOTS criteria for the methodological search.

\section{Literature analysis}

The whole process was carried out by one person under the supervision of three public health and social sciences experts, who all agreed on the interpretation. Differences of opinion were discussed until a consensus was reached, and these were all documented.

The systematic reviews included in this review were analysed in two stages based on the full texts alone, in other words without referring to the original articles collated by the systematic reviews. Firstly, the data describing the characteristics of the interventions and programmes were compiled in a summary table. Secondly, the reviews were analysed for the consideration they gave to SIH using the PRISMA-equity tool [27]. 
Table 1 Keywords used in the literature search

\begin{tabular}{|c|c|c|c|c|}
\hline Concepts & Mots-clés du MeSHa & Synonymes $^{\mathrm{b}}$ & $\mathrm{MeSH}_{\text {anglais }}{ }^{\mathrm{c}}$ & Synonymes en anglais \\
\hline promotion de la santé périnatale & $\begin{array}{l}\text { promotion de la santé } \\
\text { périnatologie }\end{array}$ & $\begin{array}{l}\text { promotion }{ }^{d} \text { santé } \\
\text { périnatalité } \\
\text { médecine périnatale }\end{array}$ & $\begin{array}{l}\text { health promotion } \\
\text { perinatalogy }\end{array}$ & $\begin{array}{l}\text { promotion }^{d} \\
\text { of health }^{\text {health promotion }}{ }^{\mathrm{d}}\end{array}$ \\
\hline promotion de la santé & promotion de la santé & & health promotion & $\begin{array}{l}\text { promotion } \\
\text { of health }\end{array}$ \\
\hline lutte contre les inégalités de santé & $\begin{array}{l}\text { disparités d'accès } \\
\text { aux soins }\end{array}$ & $\begin{array}{l}\text { autorestriction devant } \\
\text { les zoins }^{\text {inégalitéd }} \text { devant } \\
\text { les soins } \\
\text { difficultéd }^{d} \text { d'accès aux soin }^{d}\end{array}$ & healthcare disparit $^{d}$ & $\begin{array}{l}\text { health care } \\
\text { disparit }^{d} \\
\text { healthcare } \\
\text { inequalit }^{d}\end{array}$ \\
\hline inégalités sociales de santé & $\begin{array}{l}\text { disparités d'accès aux soins } \\
\text { disparités de l'état de santé } \\
\text { facteurs } \\
\text { socioéconomiques }\end{array}$ & $\begin{array}{l}\text { inégalités devant les soins } \\
\text { inégalités de l'état de santé } \\
\text { inégalités }\end{array}$ & $\begin{array}{l}\text { health care disparit } \\
\text { health status }^{\text {helth }} \\
\text { disparities } \\
\text { socioeconomic } \\
\text { factors }\end{array}$ & $\begin{array}{l}\text { healthcare inequalit }^{d} \\
\text { healthcare disparit }^{d} \\
\text { health status disparity } \\
\text { inequalities } \\
\text { inequlity }\end{array}$ \\
\hline déterminants sociaux de la santé & $\begin{array}{l}\text { déterminant social } \\
\text { de la santé }\end{array}$ & & $\begin{array}{l}\text { social determinants } \\
\text { of health }\end{array}$ & $\begin{array}{l}\text { health social } \\
\text { determinants }\end{array}$ \\
\hline $\begin{array}{l}\text { programme de santé relatif } \\
\text { à l'accompagnement à la parentalité }\end{array}$ & $\begin{array}{l}\text { pratiques éducatives } \\
\text { parentales } \\
\text { politique de santé }\end{array}$ & $\begin{array}{l}\text { éducation par les parent }^{d} \\
\text { comportement }^{d} \text { parenta }^{d} \\
\text { éducation }^{d} \text { parentale } \\
\text { fonction }^{d} \text { parentale } \\
\text { politique }^{d} \text { de santé publique } \\
\text { politique en matière } \\
\text { de santé }\end{array}$ & $\begin{array}{l}\text { parenting } \\
\text { health policy }\end{array}$ & $\begin{array}{l}\text { parenthood } \\
\text { health polic }\end{array}$ \\
\hline
\end{tabular}

${ }^{\mathrm{a}} \mathrm{MeSH}$ : medical subject heading

bynonymes: mots-clés apparaissant dans l'arborescence Mesh mais non retenus

${ }^{\mathrm{C}} \mathrm{MeSH}$ anglais: résultats produits par le CISMEF (catalogue des index des sites médicaux de langue française) à partir des mots MeSH français

${ }^{d}$ troncature ie développement limité

This tool is an extension of the PRISMA guidelines and was developed by the Campbell and Cochrane Equity Methods Group. Its aim is to take into account the notion of equity in reviews. Each of the elements of the systematic reviews (i.e. the title, abstract, introduction, method, results and discussion) was broken down and analysed to determine how the authors addressed equity.
A total of 796 publications were obtained from the literature search. Once the articles that were duplicated across the databases had been taken out and those about prematurity, maternal and infantile pathologies and children aged over three had been excluded, only 32 articles remained. The next stage allowed us to exclude articles that did not meet the AMSTAR criteria (for

Table 2 PICOTS criteria

\begin{tabular}{|c|c|c|c|}
\hline $\mathbf{P}$ & population & \multicolumn{2}{|c|}{$\begin{array}{l}\text { pregnant women } \\
\text { newborns' parents } \\
\text { newborns }\end{array}$} \\
\hline I & intervention & \multicolumn{2}{|c|}{$\begin{array}{l}\text { perinatal health: parenthood support (interventions, actions } \\
\text { and programmes) to promote the perinatal health }\end{array}$} \\
\hline C & comparator & \multicolumn{2}{|c|}{ did not concern this study } \\
\hline 0 & outcomes & \multicolumn{2}{|c|}{$\begin{array}{l}\text { favourable or unfavourable } \\
\text { outcome measures: psychosocial effects, perceived health } \\
\text { effects }\end{array}$} \\
\hline $\mathbf{T}$ & temporality & \multicolumn{2}{|c|}{ any duration of the interventions was considered } \\
\hline S & setting & $\begin{array}{l}\text { isolated } \\
\text { actions or } \\
\text { coordinates }\end{array}$ & $\begin{array}{l}\text { hospital environment } \\
\text { liberal exercise areas (city) } \\
\text { municipal, departmental services for medical } \\
\text { and social action } \\
\text { user associations, professionals }\end{array}$ \\
\hline
\end{tabular}


assessing methodological quality) and the ROBIS criteria (for assessing risk of bias) (Table 3). Finally, following a detailed analysis, 21 articles were included in the corpus (Fig. 1).

All the documents constituting the corpus were read twice. In cases of uncertainty, a second expert was consulted. In cases of disagreement between the first two experts, a third was consulted.

AP, FA, LFH carried out the documentary research protocol for the selection. For the analysis, AP read all the manuscripts twice, FA validated and, in cases of uncertainty, LFH had the final say. AL and LFH reviewed the manuscript.

\section{Results}

\section{Summary of evidence-based knowledge}

The data produced by the review were recorded in a summary table showing the type of intervention studied in each systematic review, the review's aims, and the levels of evidence such as they were analysed and described by the authors and the principal characteristics of the programmes [37-41] (Table 4).

\section{Characteristics of the reviews \\ Disciplines of the journals publishing the reviews}

The articles were drawn from journals in a variety of disciplines. A third $(n=7)$ of the publications came from public health journals. Cochrane published six reviews on the topic. The remaining publications came from journals in the field of child psychology $(n=3)$, paediatrics $(n=2)$, midwifery $(n=1)$, social work $(n=1)$ and nursing care research $(n=1)$.

\section{Authors' countries of affiliation in which the studies were conducted}

The reviews were mainly carried out by American and British authors and generally concerned interventions in the United States and the United Kingdom. There was only brief reference made to other European countries in eight of the reviews. These comprised a Finnish review, which listed only two European programmes in the 98 studies they examined [28], a Dutch review, which compared the Netherlands to the United States and Canada [29], two Cochrane reviews mentioning some studies conducted in Germany and the Netherlands $[21,30]$, two reviews that referenced Ireland [31, 32], one review mentioning interventions conducted in Switzerland [31] and another that compared Sweden with the United Kingdom [32].

\section{Aim of the reviews}

All but three systematic reviews aimed to assess the effectiveness of the programmes by evaluating their impact over a relatively short period on the mothers' and infants' wellbeing, the mothers' mental health and the mothers' adjustments to the behaviour of their babies and very young children. In three of the systematic reviews, the aim was to analyse the methods and concepts used in research relating to parenting support. One of these listed the main research areas, the methods used and the groups targeted [28]. The second studied the socioeconomic disadvantage characteristics used in research studies [29], and the third analysed the concept of preparing for parenthood [33].

\section{Principal programmes studied}

Generally, the reviews focused on the practices of the professionals; and the programmes they studied mainly involved improving parents' knowledge and skills. Three reviews looked at parental needs. One of these was a meta-analysis focusing specifically on preparation for parenthood [31]. The second examined the needs of fathers [34], and the third looked at the needs of mothers feeding their children with substitute milk [35].

\section{Principal characteristics of the interventions Recipient populations}

The reviews focused on different periods and populations:

- a specific stage in the parents' history: pregnancy $(n=3)$, the first week after giving birth $(n=1)$

- a broad timeframe from birth to three years (from birth to two months $(n=1)$, up to six months $(n=2)$, up to one year $(n=1)$, up to three years $(n=5)$

- socially disadvantaged families $(n=2)$

- teenage parents $(n=1)$

- fathers only [34] (all the others concerned mothers, parents or the couple as an entity)

- the general population through an analysis of prevention campaigns [36].

\section{Main results and conclusions}

All the reviews provided either convincing or promising data about the positive impact on mothers' and children's wellbeing of the support programmes and actions at and following birth. The programmes were found to increase the mothers' self-esteem, reduce their anger, anxiety and stress levels, improve the infants' sleep and promote the infant's language development.

\section{Three distinct levels of evidence}

In accordance with the authors' evaluations, as described and synthesised in their reviews, we grouped the evidence into three categories (this was chosen with reference to similar studies [37-41]):

1. proven evidence $(n=10)$ : this corresponded to interventions for which the review authors 


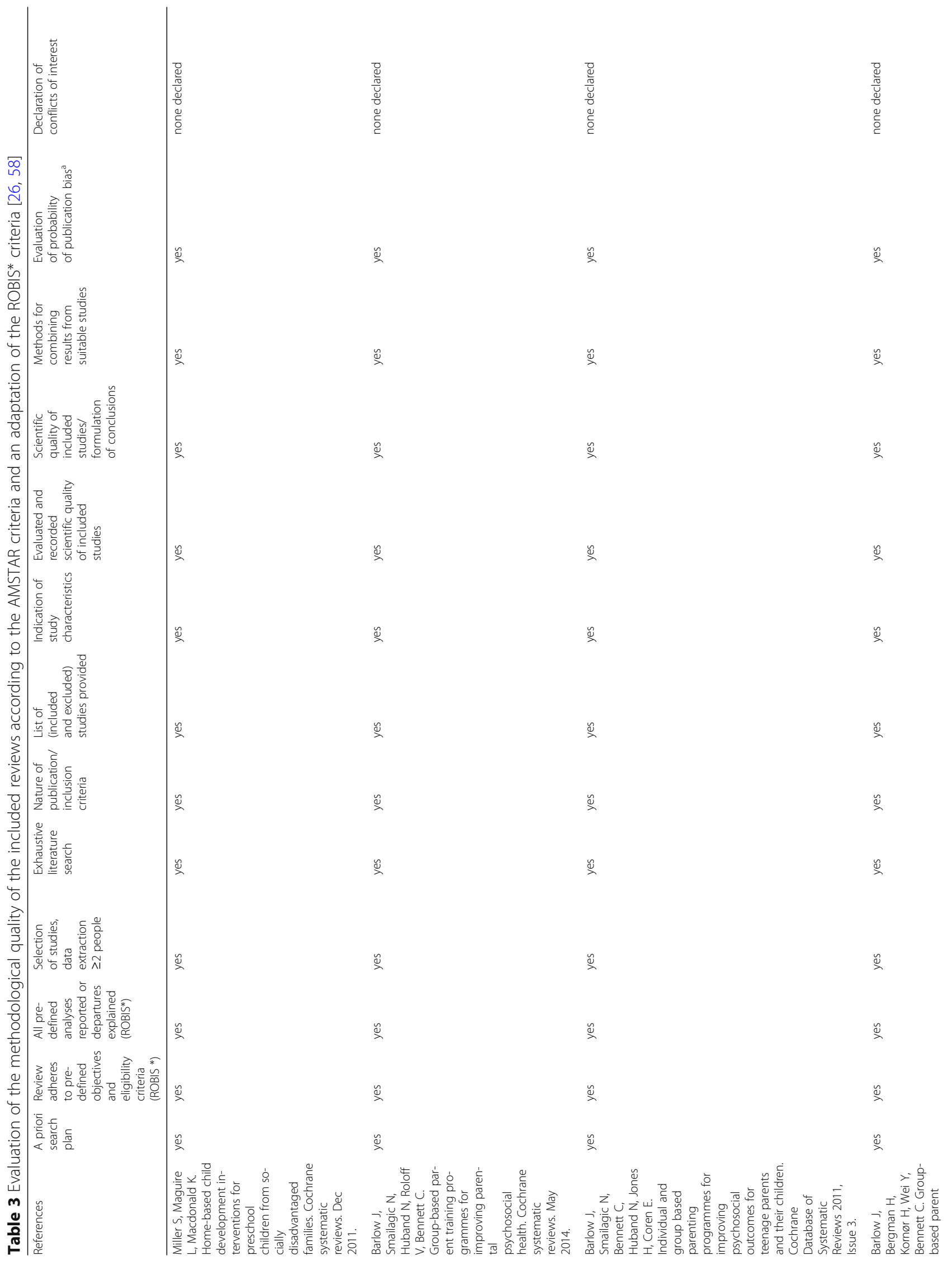




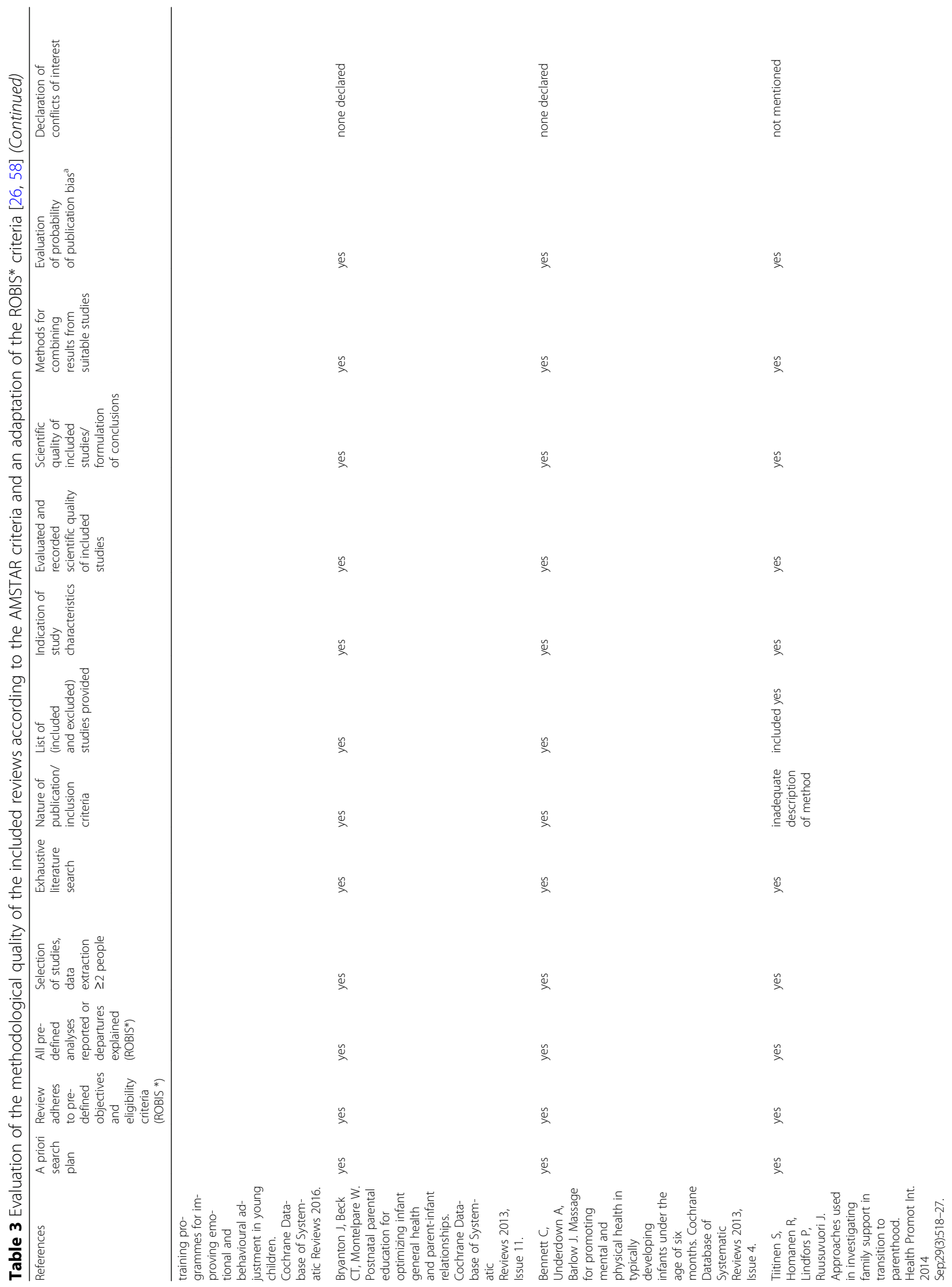




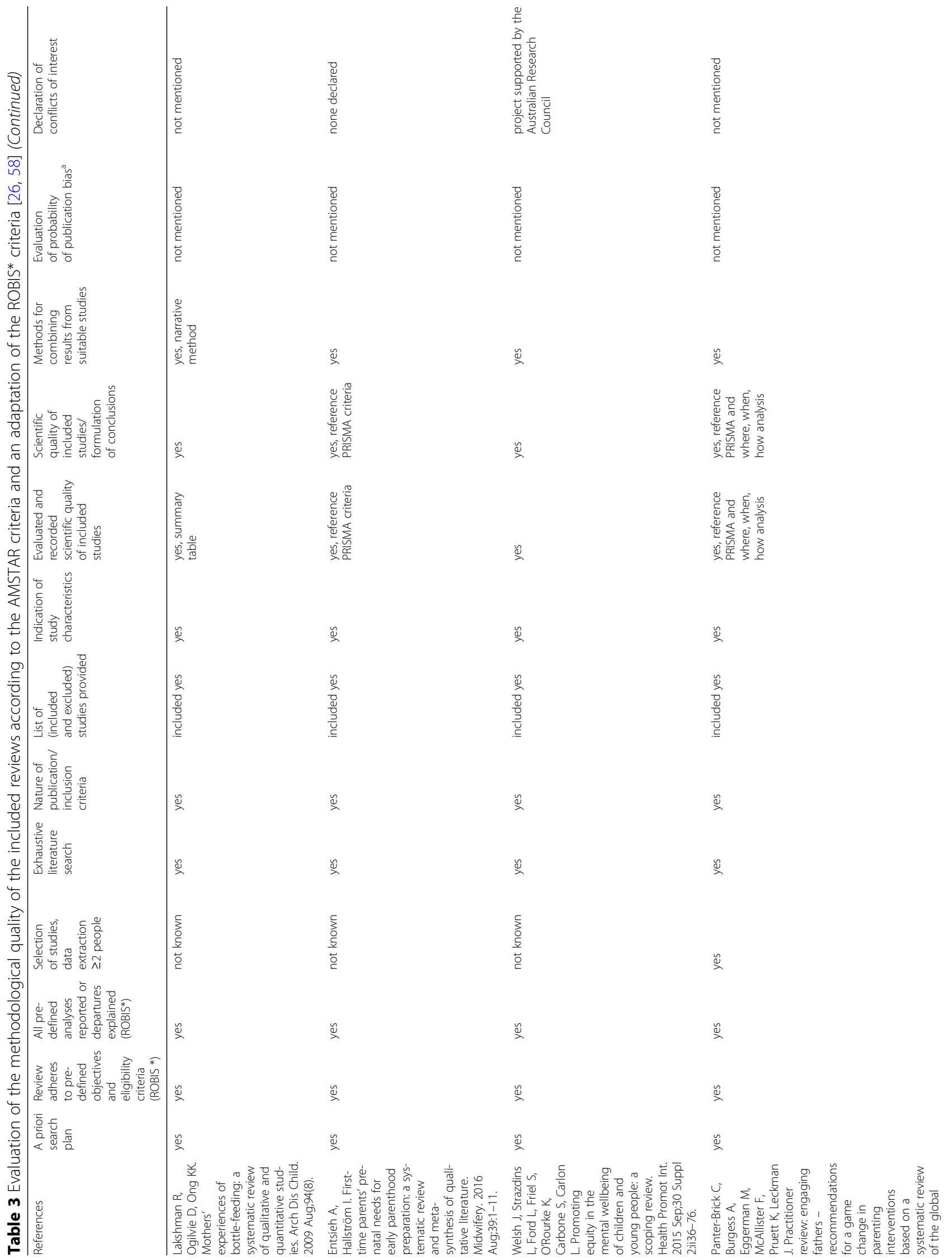




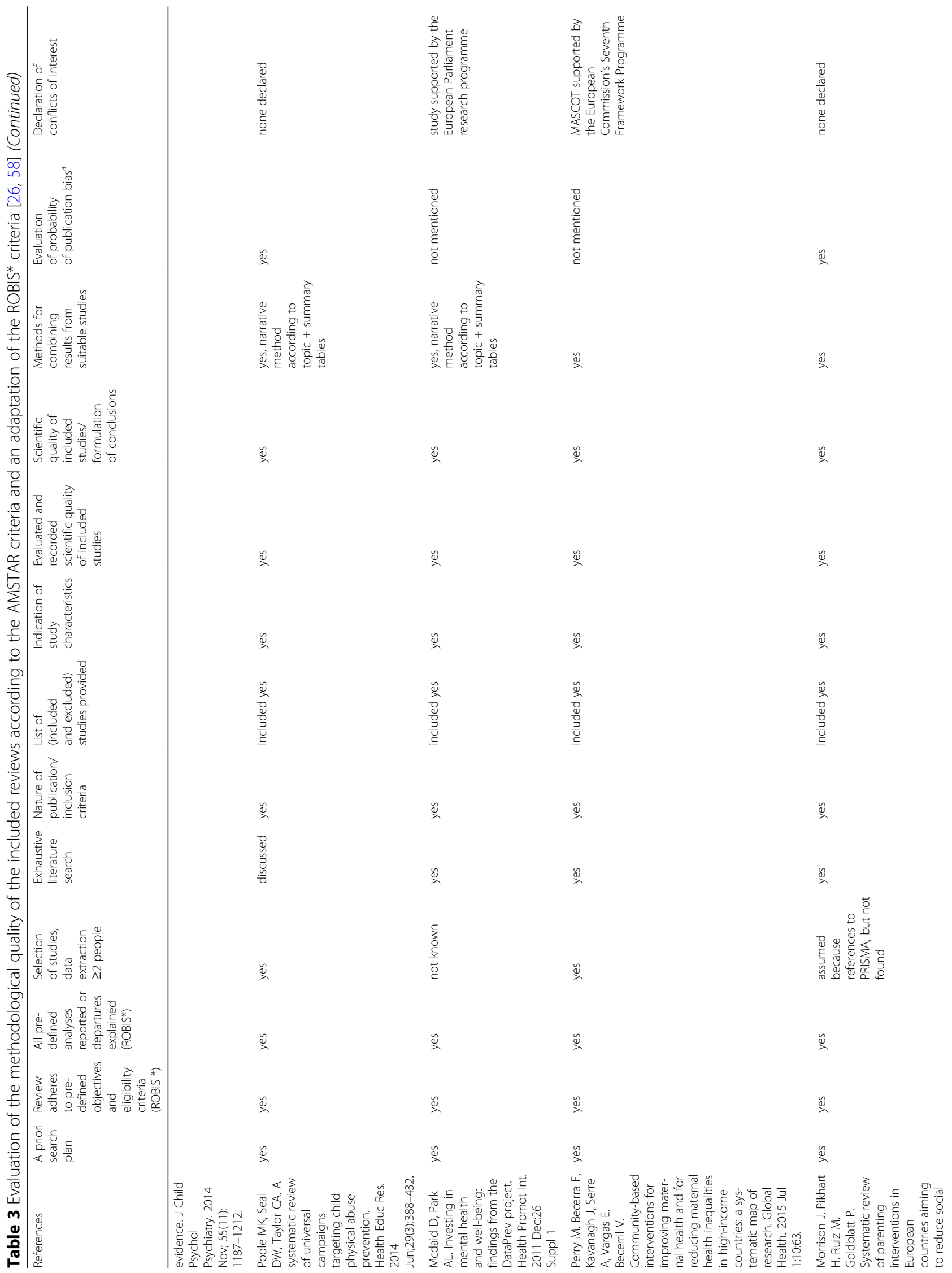




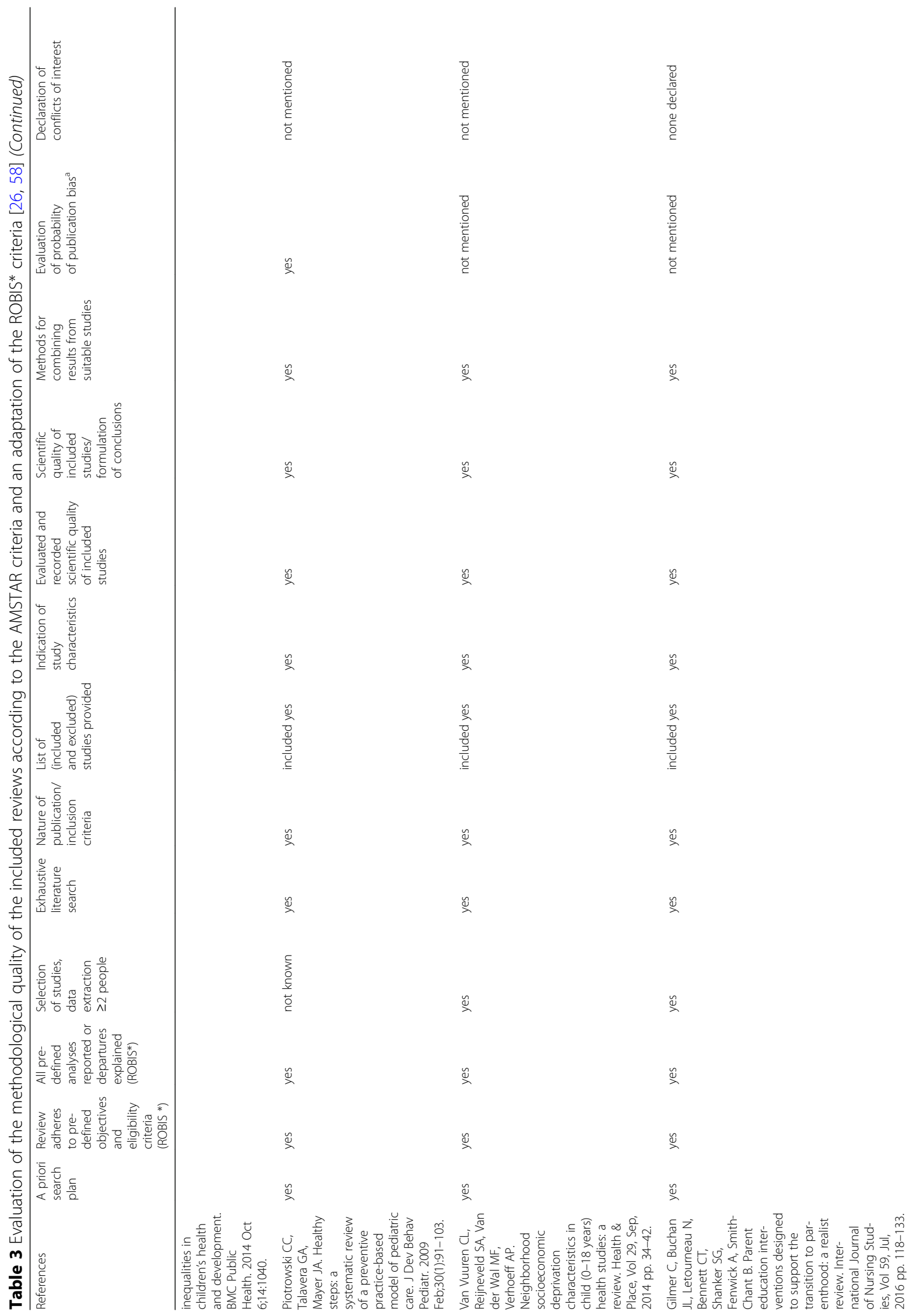


Pierron et al. BMC Public Health (2018) 18:1087

Page 10 of 27

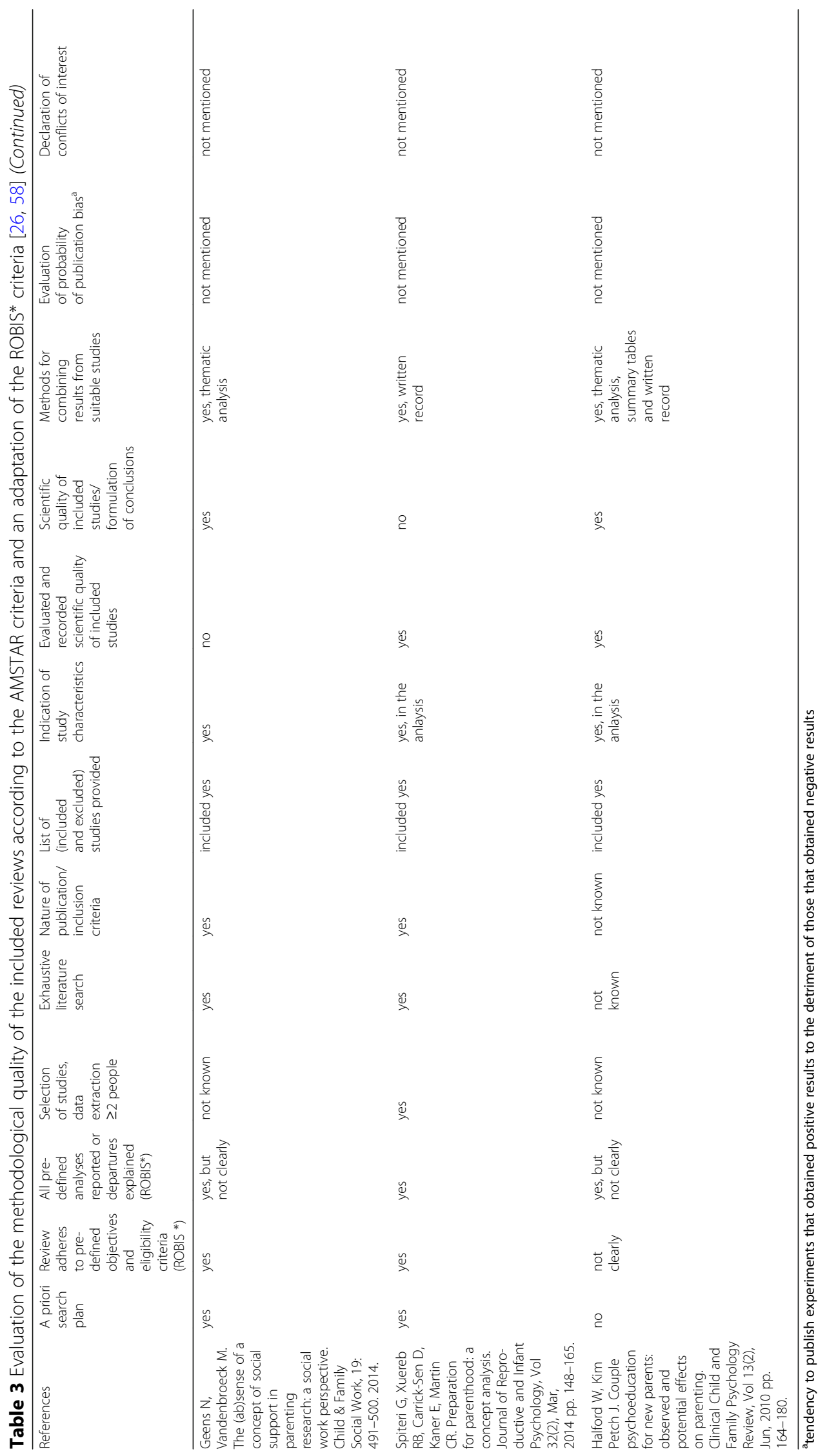




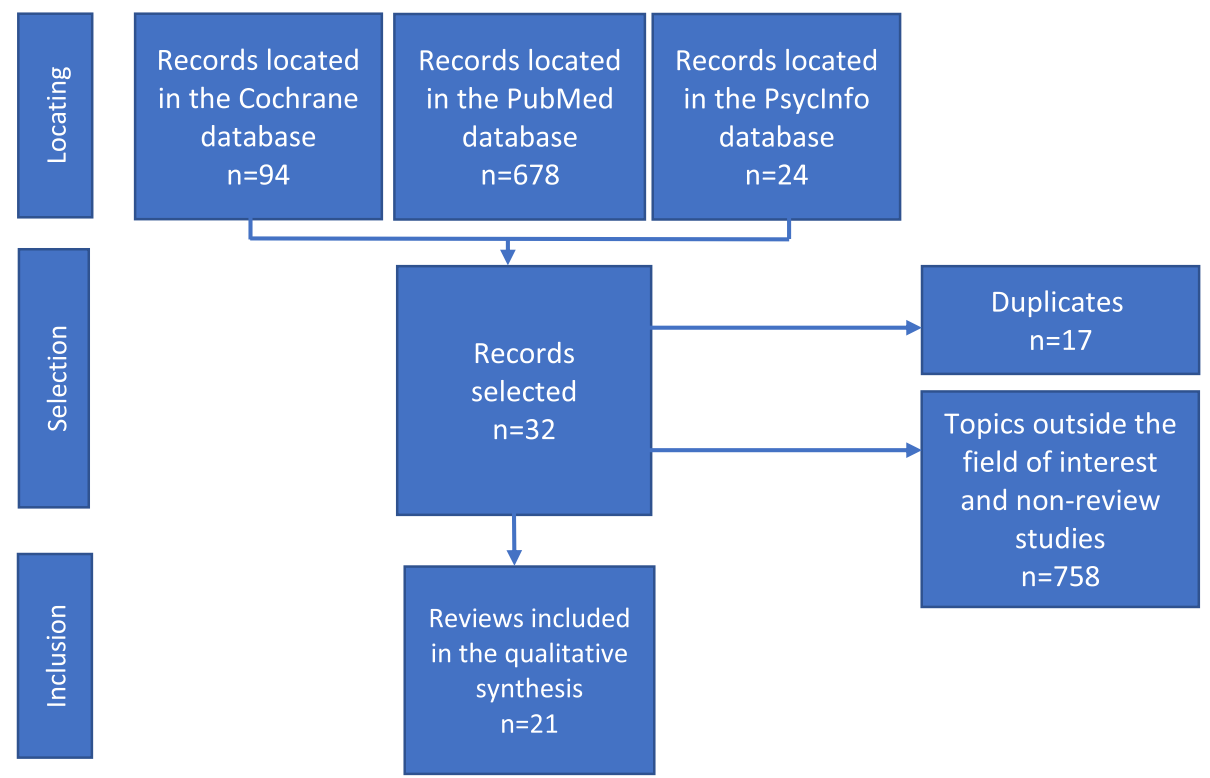

Fig. 1 Flow diagram showing the stages of article selection

concluded that the evidence was strong and unequivocal. The majority of the reviews was made up of interventions whose evidence was proven.

2. promising $(n=5)$ : this concerned intervention results based on either insufficient statistical power (linked to the fact that the samples were too small) or the fact that it was impossible to draw long-term conclusions from the results $[21,30,36,42]$.

3. lack of evidence $(n=3)$ : according to the review authors, it was difficult to evaluate the quality of evidence in the studies they analysed because either the methodological rigour was considered poor [43], it could not be objectivised [44] or there was no description of the intervention's content, implementation or results [45].

It should be noted that the two systematic reviews on research methods and the review that sought to define the concept of preparing for parenthood escaped this categorisation.

The most effective programmes Behavioural and cognitive support through therapy groups and telephone support significantly improved parents' psychosocial health [21]. Psychoeducation showed considerable potential for improving a couple's adjustment to parenthood and their awareness of and receptiveness to their newborn [46].

The most effective programmes were those begun before the birth and those in which the parents were able to actively participate [31].
Some of the reviews evaluated interventions promoting the mental health of parents during the first few years. They concluded that, for only a small financial outlay, the benefits for the mothers and babies were substantial [47].

The promising programmes One review that was carried out on eight studies concluded that parental support programmes improved parents' psychosocial health and promoted parent-child interactions. However, a lack of statistical power precluded any formal conclusion on teenage parents [30]. Based on an analysis of 48 studies in 2014, the same lead author produced proven evidence from among the general population. She concluded that group training programmes for mothers aimed at improving their children's emotional and behavioural adjustment led to a short-term reduction in stress and anger, but she added that the data was not conclusive on the long-term effects [48].

Postnatal parental education programmes seeking to optimise infants' health and parent-child relationships resulted in an improvement in sleep, in the mothers' knowledge and in the infants' sense of security. However, larger samples would have allowed a more formal conclusion to be drawn [23].

The programmes that did not prove their effectiveness The programmes carried out in the home setting to promote socially disadvantaged families' cognitive and socio-emotional development showed questionable results [44, 49]. Massage programmes aimed at boosting 


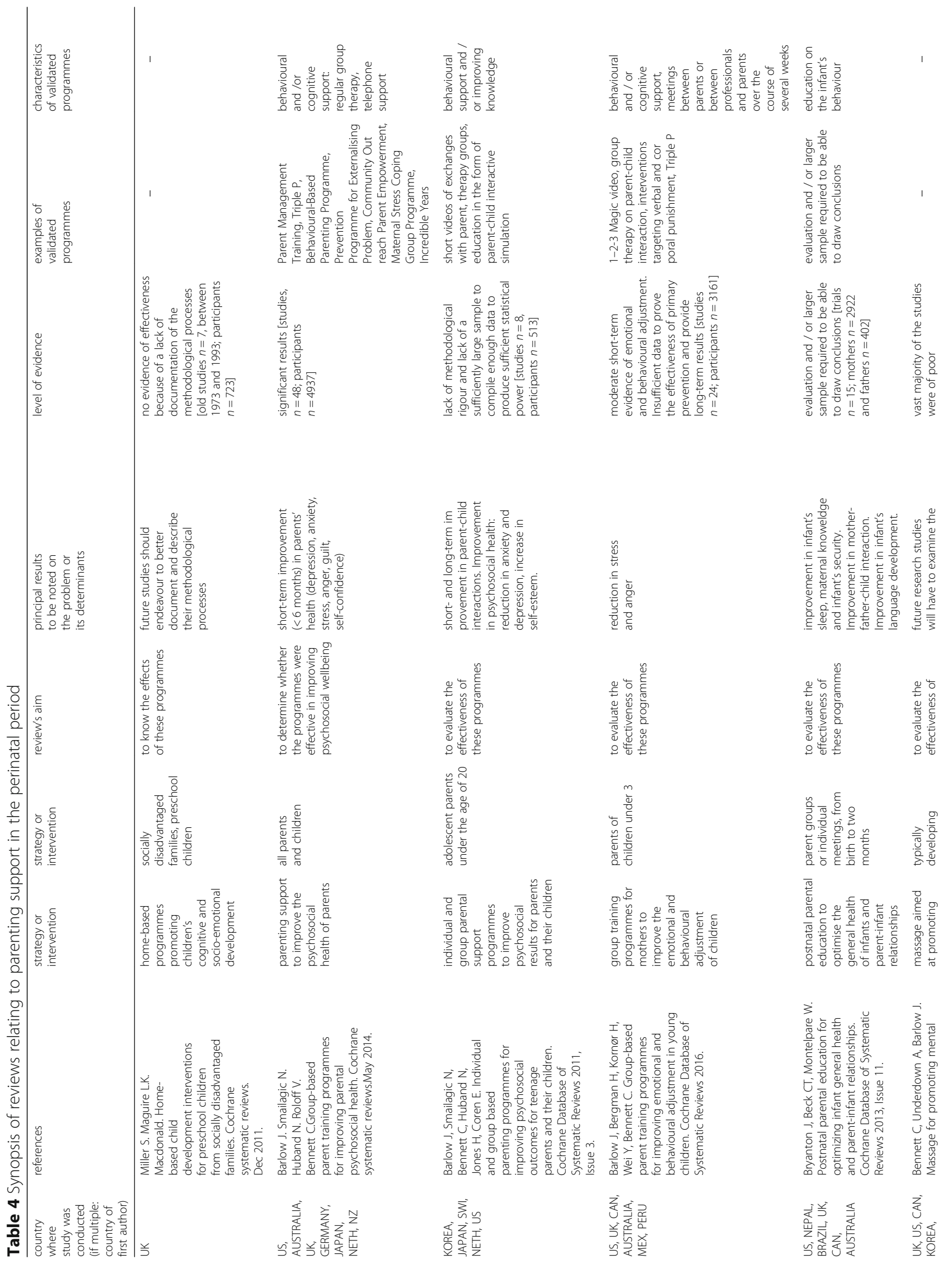




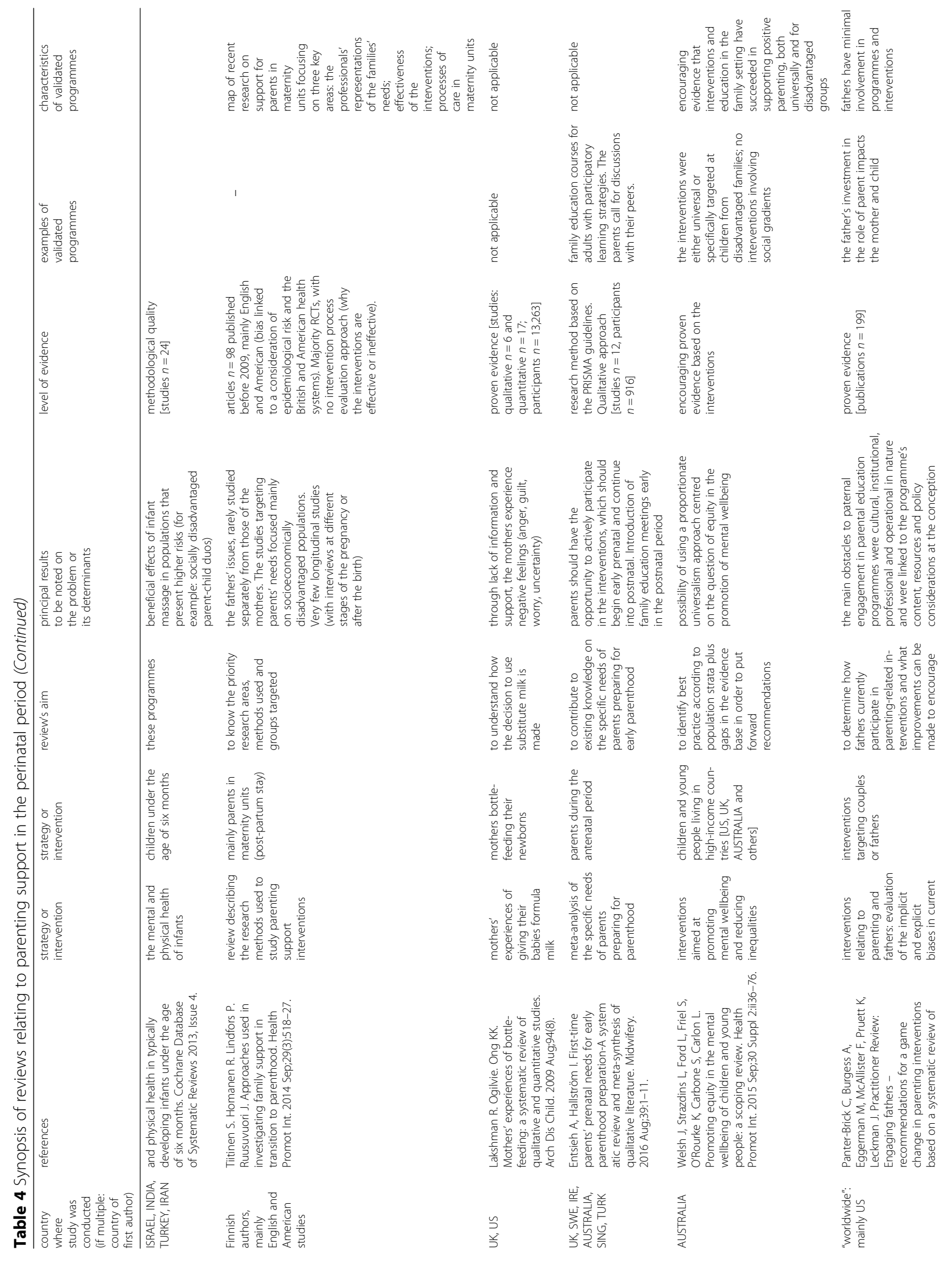




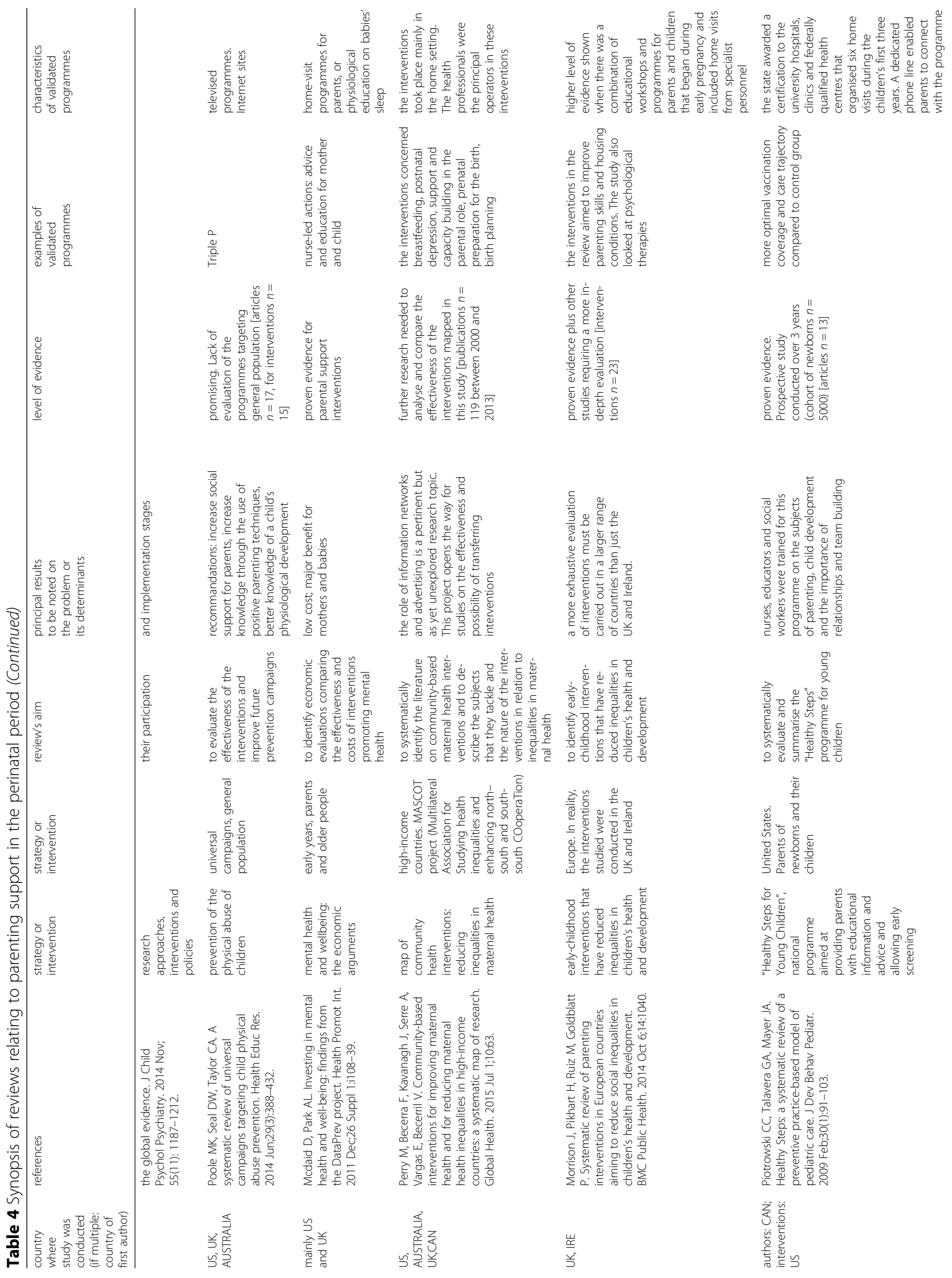




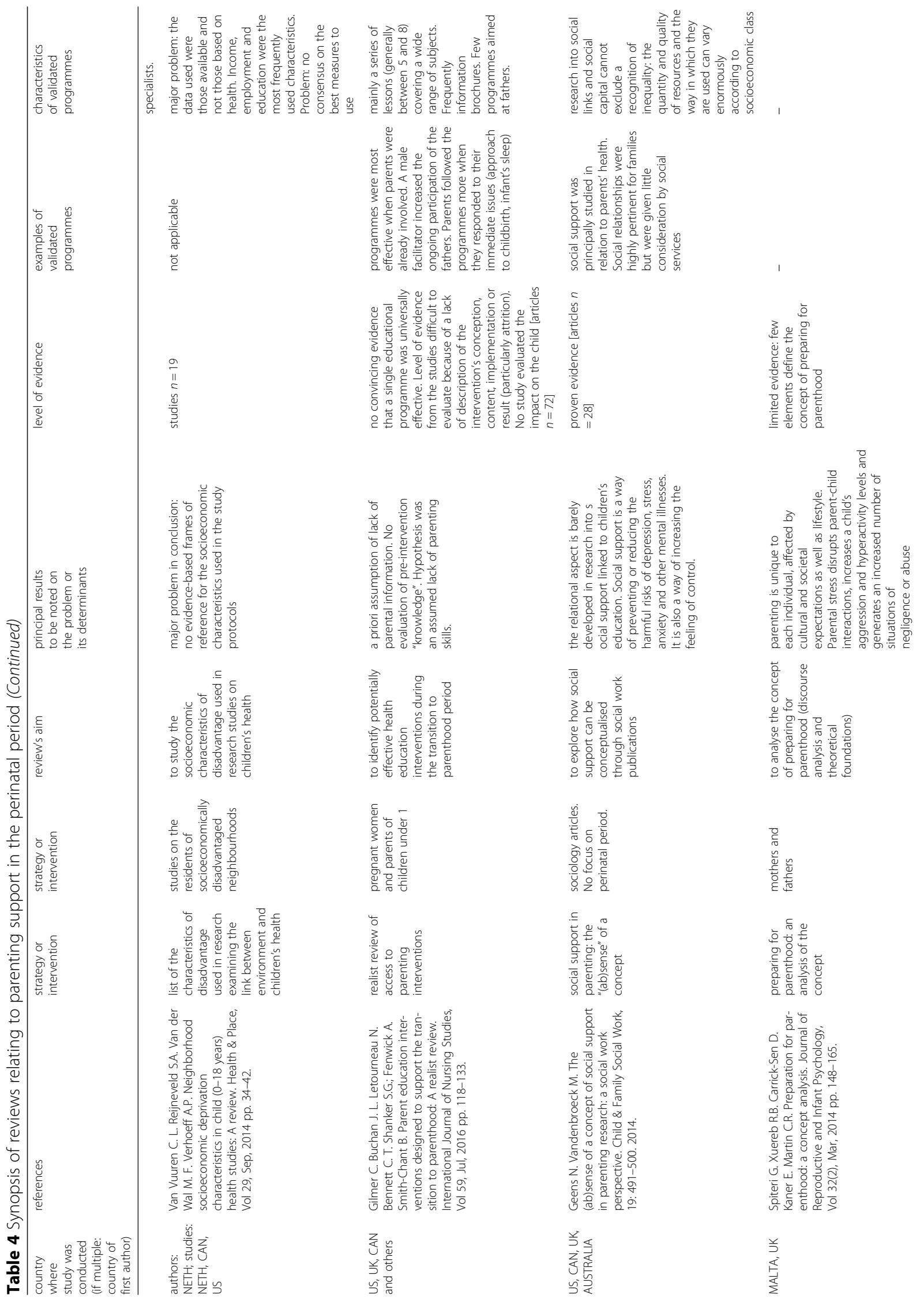




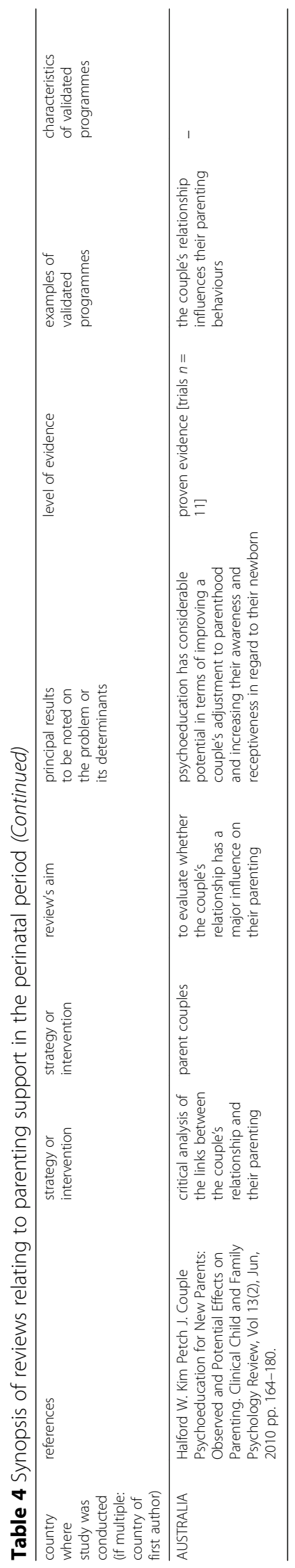


the mental and physical health of infants did not succeed in proving they were effective [43].

\section{Two key areas for improvement in parenting support programmes}

Strengthen the quality of interventions On the whole, the parental support actions viewed parents as an entity and did not differentiate the fathers' issues from those of the mothers [43]. Moreover, there were cultural and institutional obstacles to the fathers' involvement in parental education programmes, and these need to be taken into account at the design and implementation stages of programmes aimed at this particular group [34].

Parents should have the opportunity to actively participate in interventions, and these should begin in the early prenatal stage and continue into the postnatal period. Furthermore, health promotion stakeholders seem to assume a lack of parental skills. Parental knowledge should be evaluated prior to the intervention [45]. Finally, the value of peer groups is an under-researched area [30] .

Develop complementary research Longitudinal studies were extremely under-represented. Nevertheless, a paper included in the Cochrane database claimed that long-term programmes focusing on teenage parents had long-term positive influences on parent-child relationships [30]. Longitudinal studies could be conducted by carrying out interviews at different points during pregnancy or after the birth [28].

A number of authors stated that the level of evidence of an intervention's effectiveness was difficult to evaluate due to a lack of any description given of the intervention's design, content, implementation or results [43-45]. Understanding how and in what context interventions were carried out appears to be essential for the evaluative framework [28].

There are few elements that define the concept of preparing for parenthood [33].

The roles of advertising and information networks could be pertinent research topics, but they remain unexplored as yet [42].

There has been little development of the relational aspect in the research on social support $[42,50]$.

A systematic review of European studies conducted between 1999 and 2013 concluded that an evaluation of interventions must be carried out in a wider range of countries than just the United Kingdom. For example, France, Germany and Italy were not represented at all in the literature [32], thus creating an "Anglo-American bias" [28].

\section{Consideration given to $\mathrm{SIH}$ in the reviews}

To analyse the consideration given to $\mathrm{SIH}$ in efficacy analyses, each of the elements of the reviews (i.e. the title, abstract, introduction, method, results and discussion) were broken down and analysed. The results of this analysis are summarised in Table 5 .

\section{A fragmented view of the $\mathrm{SIH}$ issue in the reviews studied}

Only half of the reviews $(n=10)$ addressed the issue of $\mathrm{SIH}$. For the most part, the notions of equity related to their results and conclusions [28, 33, 34, 50, 51]. A fifth $(n=4)$ clearly integrated SIH into their analysis strategy, according to the PRISMA-equity criteria [29, 32, 42, 49].

All of the reviews that tackled the SIH question presented their results and conclusions in relation to equity [21, 29, 32, 42, 44, 49]. Three of these clearly explained their results as supporting a reduction in inequalities $[29,32,42]$, and one mentioned an increase in inequalities for some interventions [49]. A return to the original studies that were the subject of these reviews revealed that one programme, Sure Start, presented results that only seemed to benefit the most advantaged socioeconomic gradients [49].

In the studies that examined the link between children's environment and their health, there was no evidence-based for the socioeconomic characteristics used in the study protocols. However, there was "a general consensus that the combination of income, employment and education is the best way to measure household socioeconomic status" [29].

One review noted that none of the studies directly addressed housing quality as a daily living condition [32]. Very little attention was paid to childcare services in the studies (including only three referenced in Europe [32]).

Relational aspects and social links were also found to have received little research attention even though they increase the feeling of control and help prevent or reduce the risks of depression, stress and anxiety [50]. Research on social links must include a recognition of inequality because the quantity and quality of resources and how they are used can vary enormously depending on the socioeconomic class [50].

The vast majority of studies carried out dealt with at-risk populations, with little attention paid to universal services [28]. Only one review focused on community interventions [42]. Moreover, very few reviews (only three out of the 21 studies) were constructed with the aim of reducing SIH in childhood. Two of these focused on the perinatal period $[32,42]$, and the third looked at the period from childhood through to adolescence [49].

\section{An analysis of the reviews revealed effective strategies for addressing $\mathrm{SIH}$}

- There was consensus on the need to support and guide parents during the perinatal period in tackling SIH $[28,32,42,49]$. 


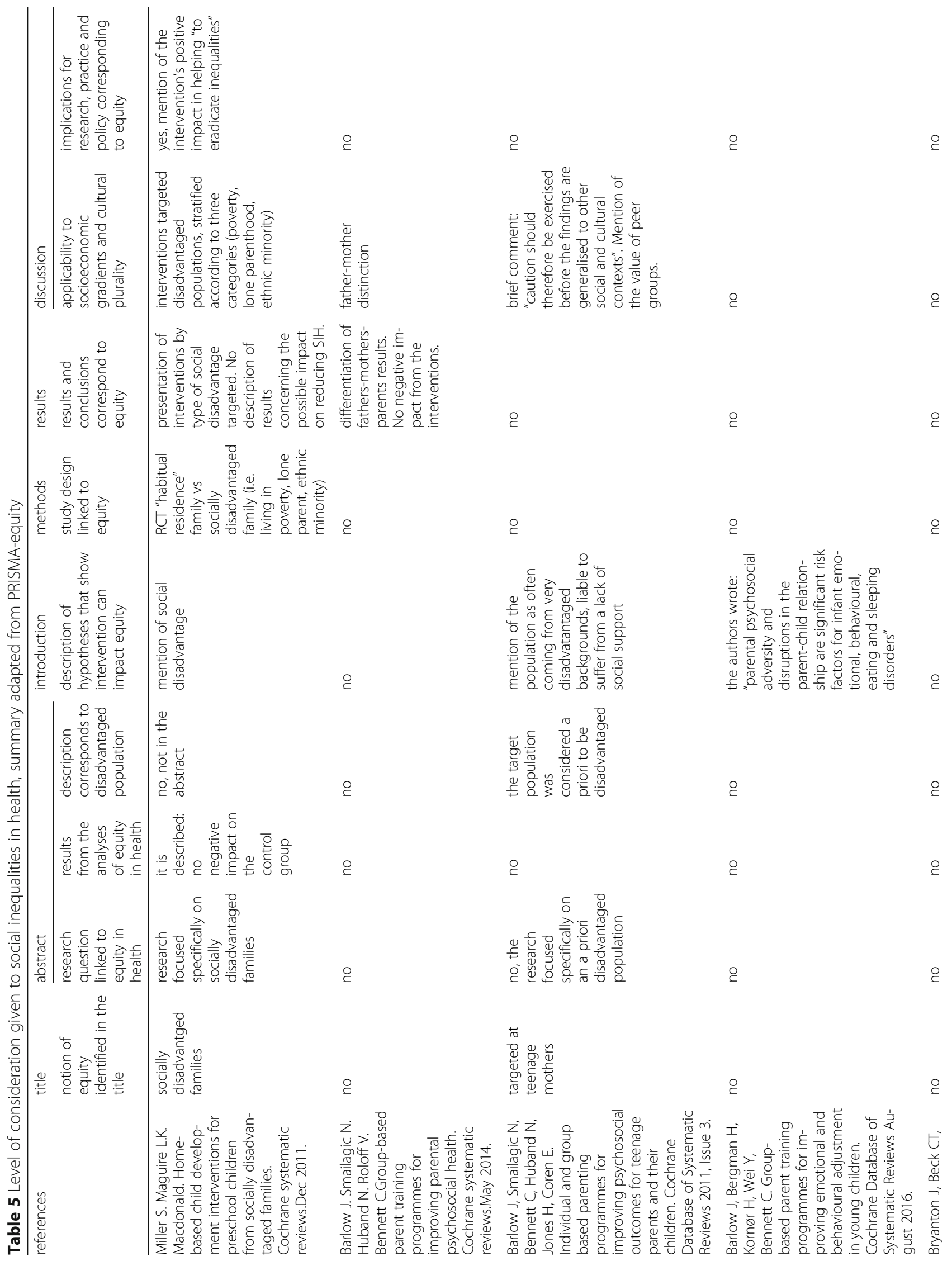




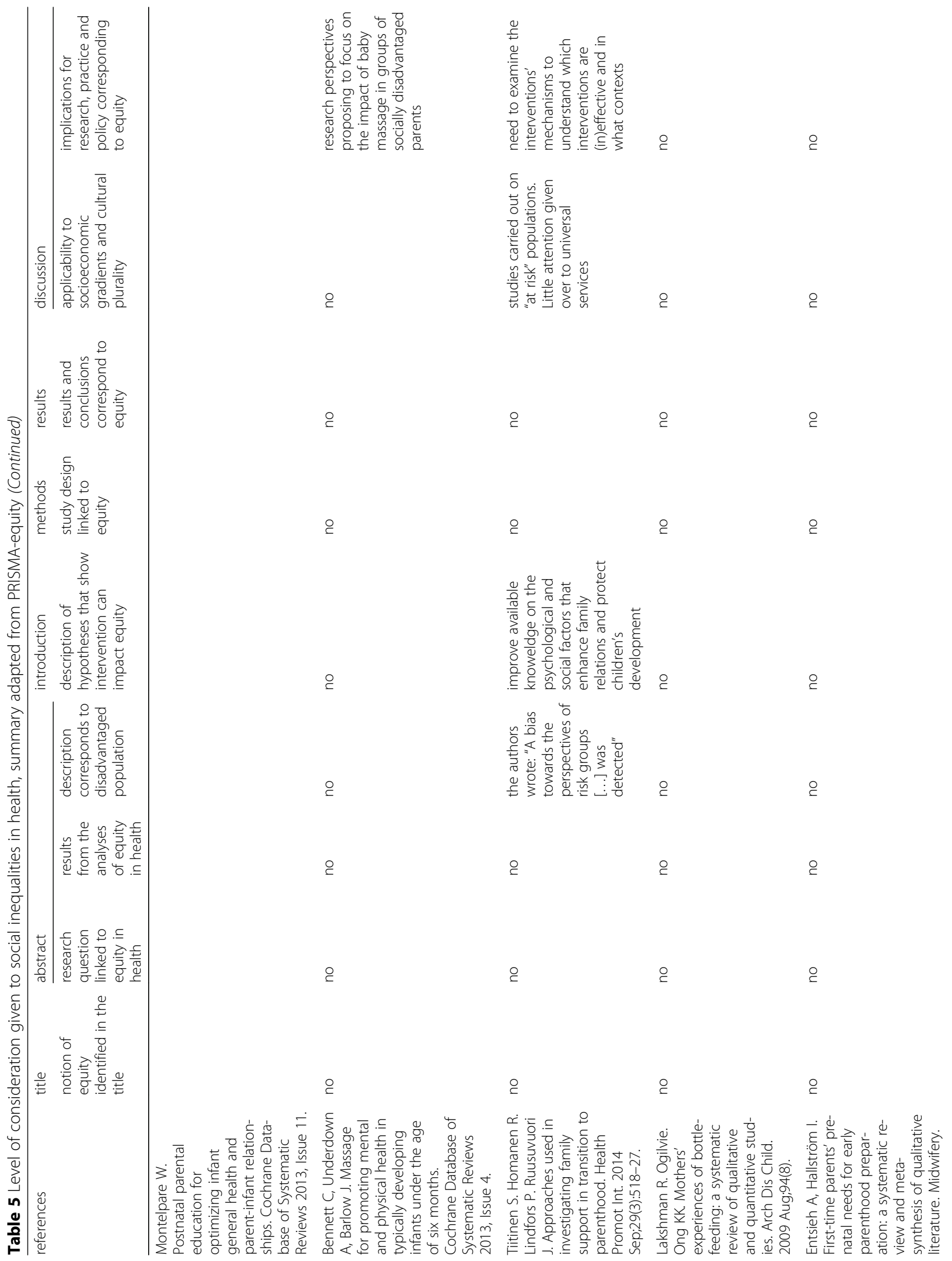




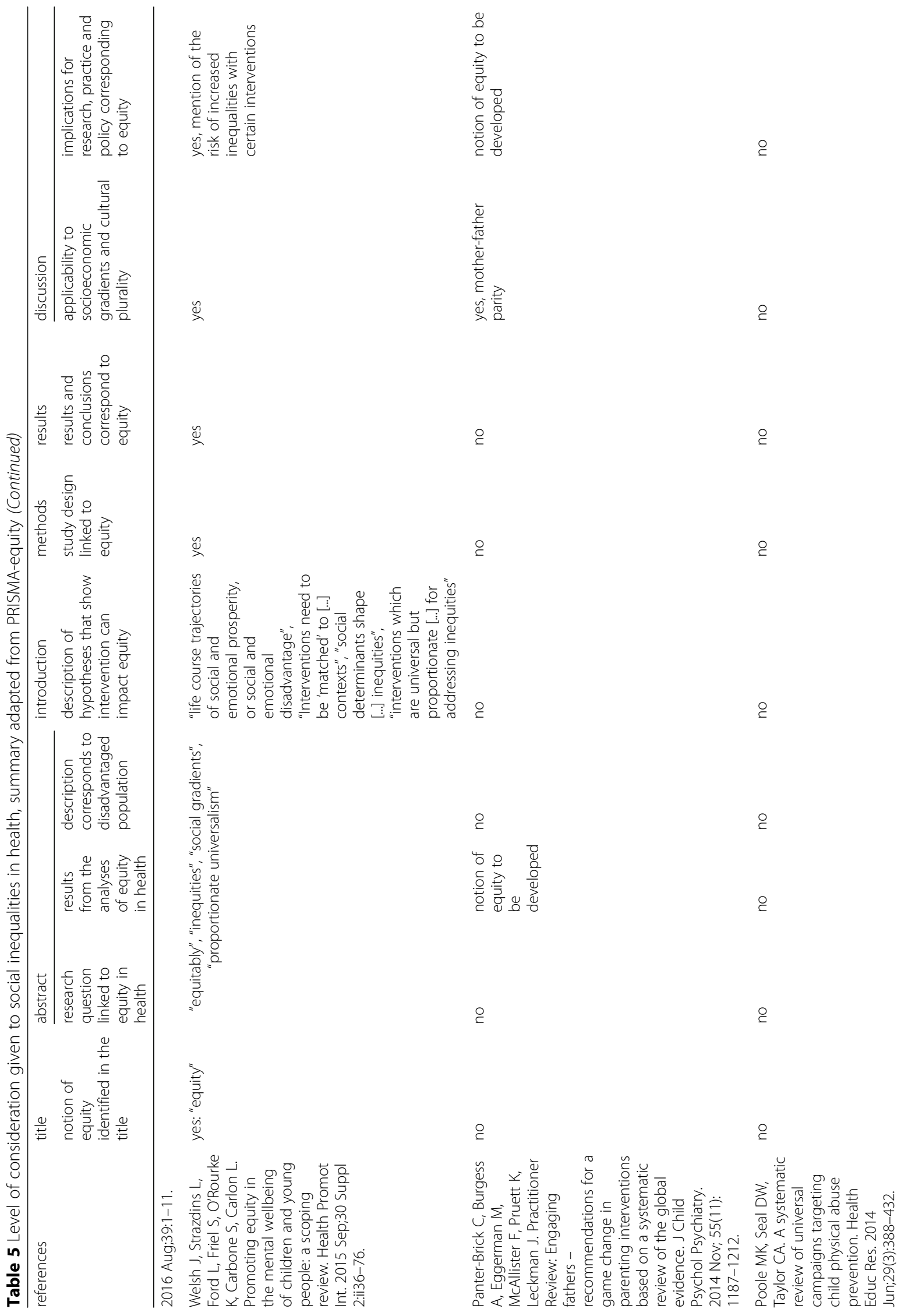




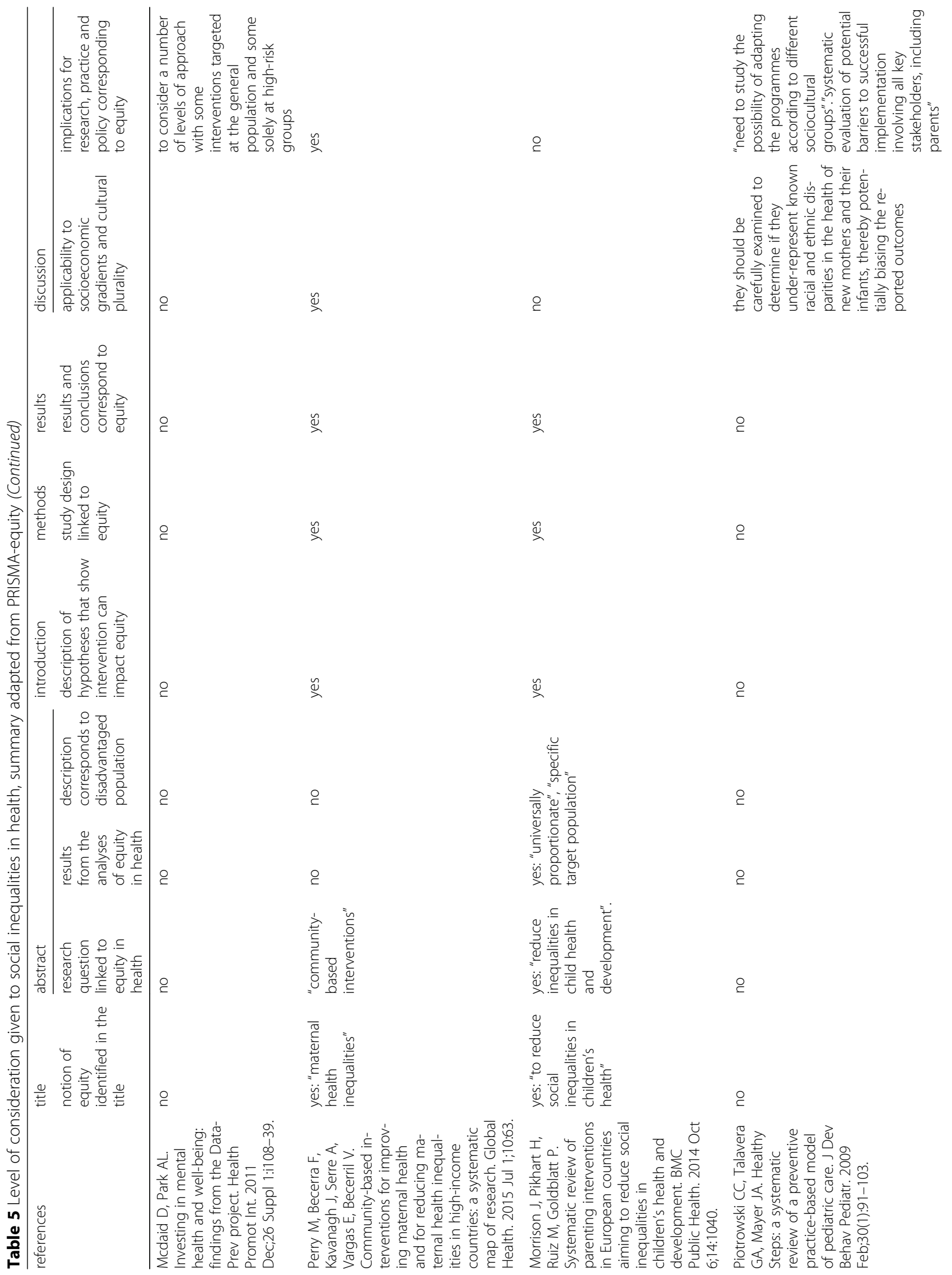




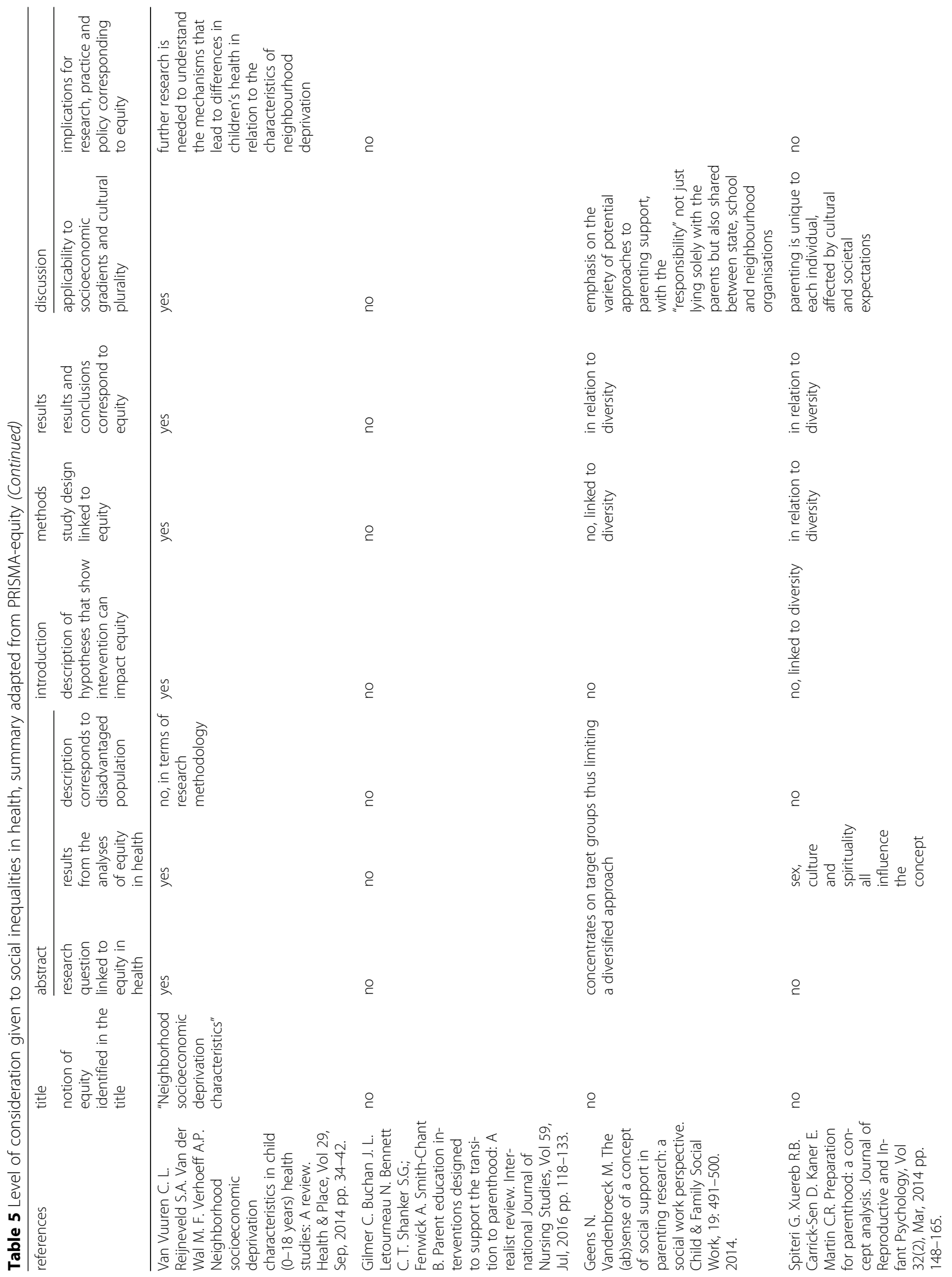




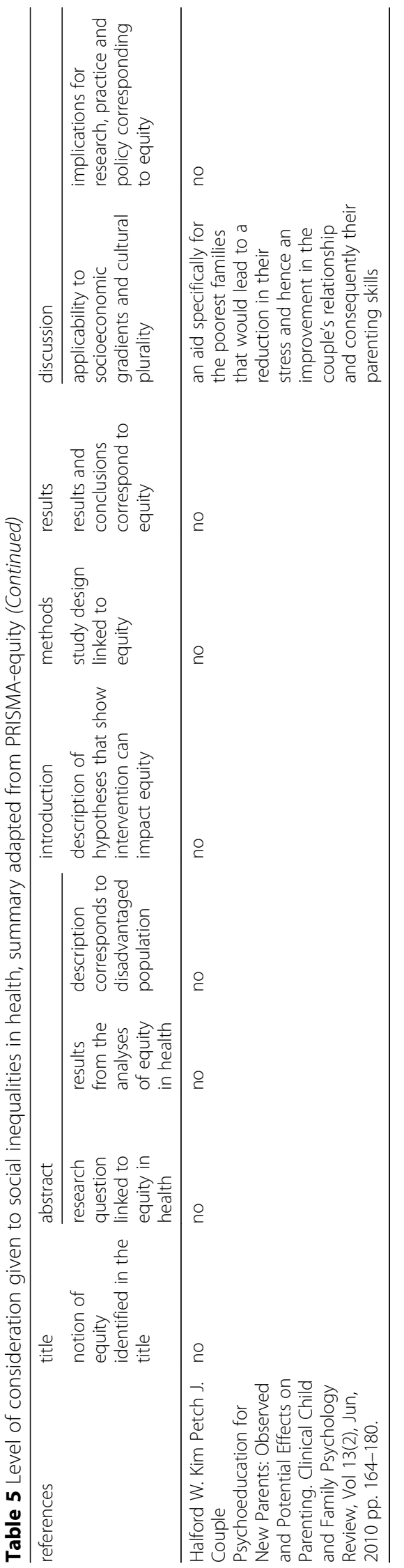


- Diversifying approaches shared between state, school and neighbourhood organisations leads to better effectiveness [50]. On the one hand, parenting does not just involve the parents [33, 45]; it also concerns their environment, including the professionals and organisations involved and their social contexts more generally. On the other, parenting is unique to each individual. It is affected by cultural and societal expectations as well as lifestyles [50].

- Proportionate universalism is a solution that was promoted by a number of reviews, most notably those of Morrison et al. (2014) and Welsh et al. (2015) [32, 49]. Michael Marmot (president of the WHO's Commission on Social Determinants of Health) explained the concept as follows: "To reduce the steepness of the social gradient in health, actions must be universal, but with a scale and intensity that is proportionate to the level of disadvantage. We call this proportionate universalism" [52]. Consequently, there is a need to explore the interventions' mechanisms to understand which interventions are (in)effective and in what contexts [21, 28, 45].

One review clearly addressed the importance of varying the interventions in accordance with neighbourhood organisations and services [50].

Morrison et al. (2014) showed that, in Europe, the most effective interventions (those with the best results and high levels of evidence) were the educational programmes that started at the beginning of pregnancy and included home visits from specialist personnel [32].

\section{Discussion}

To reiterate our main results, the reviews focused, for the most part, on the practices of the professionals. The programmes studied were mainly concerned with improving the mothers' knowledge and skills. All the reviews that described a proven or promising level of evidence showed that the parenting support programmes increased the mothers' self-esteem and reduced their anger, anxiety and stress levels and that they improved the infants' sleep.

Most authors concluded that the quality of the interventions could be improved by developing complementary research examining the interventions' content, implementation and results. These authors noted that the contexts in which the interventions took place were given little consideration since they were described either only scantly or not at all, making their evaluation difficult.

Only half of the reviews addressed the question of SIH. Most notably, the relational aspects and social links were found to have received little research attention even though they increase the feeling of control and help prevent or reduce the risks of depression, stress, anxiety and other mental illnesses.

\section{Parenthood and perinatology: Semantic notions}

Generally speaking, despite the fact the keywords "parent" and "parenting" were used, the population targeted by the reviews was mainly mothers. Issues relating to fathers or to the couple as a parental entity received little research attention. The methodological difficulty of understanding mother-father-child interactions was often mentioned by authors, although some did refer to the obvious impact of the interrelations of each family member $[23,28,34,46]$.

The notions of parenting and parenting support were found to have multiple meanings and were difficult to define because they depended on many elements. In fact, these notions had different frames of reference depending on the discipline, policy or social history in question [33, 50]. The Collins English Dictionary (online) defines "parenthood" as "the state of being a parent". The definition therefore refers as much to the father as to the mother.

The time immediately before and after a birth, that is from pregnancy to the first months of the child's life, has received little attention in the studies we have listed. Indeed, most of them focused either on the period preceding the birth or on the infant a few months old [31, 46].

\section{$\mathrm{SIH}$ and perinatal health \\ SIH and vulnerable populations}

While the actions, interventions and programmes providing support to parents were described as effective levers in addressing SIH, very few were designed with equity in health as their primary objective.

When authors did address SIH, their reviews mainly targeted population categories such as teenage parents and culturally or economically disadvantaged families. This strategy represents only one reductive vision of $\mathrm{SIH}$ and does not, in any way, take into account social gradients. The more socioeconomically disadvantaged an individual's situation is, the worse their health will be.

This can be observed across the whole social spectrum. Every level in the socioeconomic stratification of the population is affected by SIH [5, 6]. Only one review of all those studied demonstrated the pertinence and effectiveness of a strategy constructed on proportionate universalism $[49,53]$.

A small number of the reviews (those constructed with equity in health as a clear objective) made reference to an approach that goes beyond the notions of high- or low-risk categorisation according to individual living conditions. One of these examined the value of considering neighbourhood in terms of approximating the notion of socioeconomic deprivation [29].

\section{$\mathrm{SIH}$ and norms}

The fact that the majority of actions were carried out by professionals for the benefit of parents raises the implicit 
question of a ranking of knowledge [32, 45, 51]. In this sense, traditional types of knowledge, such as group knowledge or that passed on from mother to daughter, tend to be devalued. It is interesting, nevertheless, to note that the notion of childcare emerged as a result of the drive for healthcare control, which was based on a medical discourse that was both injunctive and normative [54]. However, it seems that programmes and actions could be made more effective if they were constructed within a diagnostic approach that is shared between parents, professionals and institutions [28, 31, 34, 49].

The mobilisation of peer groups and the active participation of recipient populations were described as strategies that would increase the effectiveness of actions. The representations of the different stakeholders, whether in terms of their expectations or their needs, still appear to be negligible in programme development. The controversial results from the home-based programmes for socially disadvantaged families [36, 47] could be explained in part by these divergent viewpoints.

\section{SIH and the social determinants of health Take action early}

This review of reviews has identified the most effective actions on health. Therapy groups and telephone support significantly improve parents' psychosocial health. Psychoeducation programmes that are begun before birth and which allow parents the opportunity to actively participate are the most effective $[29,41]$.

\section{Act with the families}

Facilitators or difficulties in setting up the actions were never described. This review of reviews has also revealed, in particular, an assumed lack of knowledge among parents and even a lack of analysis of the relational modalities between the professionals and the parents [21, 31, 35, 45, 48]. Collaboration involves the need for a common language between professionals from different disciplines, parents with multiple issues with different objectives. This review has shown, however, that studies focusing on the ability to listen and the quality of the professionals-mothers-parents-newborns relationship are under-represented [35, 44]. Highlighting and theorising these interrelations represents an approach to understanding how interventions function, which enables them to be made more effective [55-57].

\section{Act in interaction with the context}

The ability of each person to take action to improve their health depends much on the social context in which they live, think and work. Health promotion does not just concern health services but also the social determinants of health that make up this context [54-56].
Social determinants have been widely shown to have a strong influence on health $[2,5,6,53]$.

Proposing programmes and actions to tackle SIH therefore calls for a global, dynamic approach to its social determinants. An analysis of the relationships between the social, economic, cultural and environmental contexts in which these projects are rolled out would allow us to understand the functioning of these interventions.

\section{Theorise to act}

Almost all the reviews highlighted the lack of description given to the intervention development processes. A number of authors noted that the interventions were evaluated on their effectiveness but that insufficient information had been given about the interventions' settings or their populations [28, 34, 44]. This lack of contextual elements raises the question of the transferability of the programmes or actions described in the reviews analysed. For example, many programmes focused on parents' knowledge and skills but neglected to first define the specific needs of the populations targeted. It is therefore difficult to demonstrate their effectiveness and to envisage their adaptation to other contexts.

\section{Limitations of this review}

While many public health journals value publications from the human and social sciences, this synthesis of knowledge was carried out using only bibliographic health databases. As a result, it has undoubtedly overlooked certain elements within the sociological approaches.

The methodological choice to synthesise knowledge using articles from scientific journals precluded us from analysing public health policies or the social policies that these programmes and actions were interacting with.

It should be noted that the reviews we studied were written in English, which could have led to a possible selection bias. If this was the case, the bias remained limited since the majority of scientific publications are written in English.

Because the reviews focused on high-income countries, the results of this study cannot be extrapolated to low income countries, where the situations may be different.

\section{Conclusions}

This focus on the current knowledge concerning action on social inequalities in perinatal health shows that the approach remains both modest and reductive. On the one hand, very few authors have considered the notion of equity in health, and, on the other, the vision of SIH remains limited. Parental programmes focused, for the most part, only on the mothers, and the actions tended to target the most disadvantaged populations, with no consideration of the social gradients of health. 
This review shows that the majority of the publications came from English-speaking countries. Currently, to our knowledge, no study has been carried out in Europe on parenting support as a means of addressing $\mathrm{SIH}$ among mothers and their newborns.

Parenting support interventions are complex. Their effects are variable, and they result from multiple actions, with the different stakeholders interacting in and with a particular dynamic environment. In future research, the methodological challenge will be to understand how, for whom and in what conditions interventions function.

\section{Abbreviations \\ AMSTAR: Assessing the Methodological Quality of Systematic Reviews; MeSH: Medical Subject Heading; PRISMA: Preferred Reporting Items for Systematic Reviews and Meta-Analyses; SIH: Social inequalities in health; WHO: World Health Organization}

\section{Acknowledgements}

Clare Ferguson for the translation and Céline Aubert, documentalist at the Faculté de Médecine in Nancy.

\section{Authors' contributions}

AP, FA, LFH carried out the documentary research protocol for the selection. For the analysis, AP read all the manuscripts twice, FA validated and, in cases of uncertainty, LFH had the final say. AL and LFH reviewed the manuscript

All authors read and approved the final manuscript.

Ethics approval and consent to participate Not applicable.

\section{Consent for publication}

Not applicable.

\section{Competing interests}

The authors declare that they have no competing interests.

\section{Publisher's Note}

Springer Nature remains neutral with regard to jurisdictional claims in published maps and institutional affiliations.

\section{Author details \\ ${ }^{1}$ Université de Lorraine, EA4360 APEMAC, Vandoeuvre-lès-Nancy, France ${ }^{2}$ Luxembourg Institute of Health, Department of Population Health, 1 A-B Rue Thomas Edison, Strassen 1445, Luxembourg. ${ }^{3}$ Société Française de Santé Publique, 1 rue de la forêt, Laxou 54520, France. ${ }^{4} \mathrm{CHU}$ INSERM. Bordeaux Population Health Research Center. UMR 1219 CIC-EC 1401, Université de Bordeaux, Bordeaux, France.}

Received: 30 December 2017 Accepted: 27 July 2018

Published online: 31 August 2018

\section{References}

1. Organisation Mondiale de la Santé, Bureau Régional Europe. Environment and health risks: a review of the influence and effects of social inequalities. Copenhagen. 2010:268

2. Pickett KE, Wilkinson RG. Income inequality and health: a causal review. Soc Sci Med. 2015;128:316-26.

3. Wilkinson RG, Pickett KE. Income inequality and socioeconomic gradients in mortality. Am J Public Health. 2008;98(4):699-704.

4. Wilkinson RG, Pickett KE. Income inequality and population health: a review and explanation of the evidence. Soc Sci Med. 2006;62(7):1768-84.

5. Jakab Z, Marmot M. Social determinants of health in Europe. Lancet. 2012; 379(9811):103-5

6. Marmot M. Social determinants of health inequalities. Lancet. 2005; 365(9464):1099-104.
7. World Health Organization regional office for Europe. First WHO Conference on the New European Policy for Health. Health 2020. Available from: http:// www.euro.who.int/_data/assets/pdf_file/0020/154253/Health-2020-Conf.Interim-second-report-on-social-determinants-...pdf?ua=1

8. World Health Organization. Closing the gap in a generation: health equity through action on the social determinants of health. In: Final Report of the Commission on Social Determinants of Health. Geneva: CSDH; 2008.

9. Kuh D, Ben-Shlomo Y, Lynch J, Hallqvist J, Power C. Life course epidemiology. J Epidemiol Community Health. 2003;57(10):778-83.

10. Vandecasteele L. Life course risks or cumulative disadvantage? The structuring effect of social stratification determinants and life course events on poverty transitions in Europe. Eur Sociol Rev. 2011;27(2):246-63.

11. Shanahan MJ. Pathways to adulthood in changing societies: variability and mechanisms in life course perspective. Annu Rev Sociol. 2000;26:667-92.

12. Guyer B, Ma S, Grason H, Frick KD, Perry DF, Sharkey A, et al. Early Childhood Health Promotion and Its Life Course Health Consequences. Acad Pediatr. 2009;9(3):142-9. e71

13. Shonkoff JP, Garner as, the committee on psychosocial aspects of child and family health, committee on early childhood, adoption, and dependent care, and section on developmental and behavioral pediatrics, Siegel BS, Dobbins Ml, Earls MF, et al. The lifelong effects of early childhood adversity and toxic stress. Pediatrics. 2012;129(1):e232-46.

14. Feinberg $A P$, Fallin MD. Epigenetics at the crossroads of genes and the environment. JAMA. 2015;314(11):1129.

15. McGowan PO, Sasaki A, D'Alessio AC, Dymov S, Labonté B, Szyf M, et al. Epigenetic regulation of the glucocorticoid receptor in human brain associates with childhood abuse. Nat Neurosci. 2009;12(3):342-8.

16. Weaver ICG, Cervoni N, Champagne FA, D'Alessio AC, Sharma S, Seckl JR, et al. Epigenetic programming by maternal behavior. Nat Neurosci. 2004;7(8): 847-54.

17. Fumagalli F, Bedogni F, Perez J, Racagni G, Riva MA. Corticostriatal brainderived neurotrophic factor dysregulation in adult rats following prenatal stress. Eur J Neurosci. 2004;20(5):1348-54.

18. Maccari S, Darnaudery M, Morley-Fletcher S, Zuena AR, Cinque C, Van Reeth O. Prenatal stress and long-term consequences: implications of glucocorticoid hormones. Neurosci Biobehav Rev. 2003;27(1-2):119-27.

19. Heijmans BT, Tobi EW, Stein AD, Putter H, Blauw GJ, Susser ES, et al. Persistent epigenetic differences associated with prenatal exposure to famine in humans. Proc Natl Acad Sci. 2008;105(44):17046-9.

20. Vaiserman AM. Epigenetic programming by early-life stress: evidence from human populations. Dev Dyn. 2015;244(3):254-65.

21. Barlow J, Smailagic N, Huband N, Roloff V, Bennett C. Group-based parent training programmes for improving parental psychosocial health. Cochrane Database of Syst Rev 2014, Issue 5. Art. No.: CD002020. https://doi.org/10. 1002/14651858.CD002020.pub4.

22. Gagnon AJ, Sandall J. Individual or group antenatal education for childbirth or parenthood, or both. Cochrane Database of Syst Rev 2007, Issue 3. Art. No.: CD002869. https://doi.org/10.1002/14651858.CD002869.pub2.

23. Bryanton J, Beck CT, Montelpare W. Postnatal parental education for optimizing infant general health and parent-infant relationships. Cochrane Database of Syst Rev 2013, Issue 11. Art. No.: CD004068. https://doi.org/10. 1002/14651858.CD004068.pub4.

24. Moher D, Liberati A, Tetzlaff J, Altman DG. Preferred reporting items for systematic reviews and meta-analyses: the PRISMA statement. BMJ. 2009; 339:b2535.

25. Shamseer L, Moher D, Clarke M, Ghersi D, Liberati A, Petticrew M, et al. Preferred reporting items for systematic review and meta-analysis protocols (PRISMA-P) 2015: elaboration and explanation. BMJ. 2015;349(jan02 1):g7647.

26. Shea BJ, Grimshaw JM, Wells GA, Boers M, Andersson N, Hamel C, et al. Development of AMSTAR: a measurement tool to assess the methodological quality of systematic reviews. BMC Med Res Methodol. 2007;7:10.

27. Burford BJ, Welch V, Waters E, Tugwell P, Moher D, O'Neill J, et al. Testing the PRISMA-equity 2012 reporting guideline: the perspectives of systematic review authors. PLoS One. 2013;8(10):e75122.

28. Tiitinen $\mathrm{S}$, Homanen R, Lindfors $\mathrm{P}$, Ruusuvuori J. Approaches used in investigating family support in transition to parenthood. Health Promot Int. 2014;29(3):518-27.

29. van Vuuren $\mathrm{CL}$, Reijneveld $\mathrm{SA}$, van der Wal MF, Verhoeff AP. Neighborhood socioeconomic deprivation characteristics in child (0-18 years) health studies: a review. Health Place. 2014;29:34-42. 
30. Barlow J, Smailagic N, Bennett C, Huband N, Jones H, Coren E. Individual and group based parenting programmes for improving psychosocial outcomes for teenage parents and their children. Cochrane Database of Syst Rev 2011, Issue 3. Art. No.: CD002964. https://doi.org/10.1002/14651858.CD002964.pub2.

31. Entsieh AA, Hallström IK. First-time parents' prenatal needs for early parenthood preparation-a systematic review and meta-synthesis of qualitative literature. Midwifery. 2016;39:1-11.

32. Morrison J, Pikhart H, Ruiz M, Goldblatt P. Systematic review of parenting interventions in European countries aiming to reduce social inequalities in children's health and development. BMC Public Health. 2014;14:1040.

33. Spiteri G, Xuereb RB, Carrick-Sen D, Kaner E, Martin CR. Preparation for parenthood: a concept analysis. J Reprod Infant Psychol. 2014;32(2):148-65.

34. Panter-Brick C, Burgess A, Eggerman M, McAllister F, Pruett K, Leckman JF. Practitioner review: engaging fathers--recommendations for a game change in parenting interventions based on a systematic review of the global evidence. J Child Psychol Psychiatry. 2014;55(11):1187-212.

35. Lakshman R, Ogilvie D, Ong KK. Mothers' experiences of bottle-feeding: a systematic review of qualitative and quantitative studies. Arch Dis Child. 2009;94(8):596-601.

36. Poole MK, Seal DW, Taylor CA. A systematic review of universal campaigns targeting child physical abuse prevention. Health Educ Res. 2014;29(3): 388-432.

37. Guillemont J, Clément J, Cogordan C, Lamboy B. Interventions validées ou prometteuses en prévention de la consommation d'alcool chez les jeunes: synthèse de la littérature, Evidence-based and promising interventions to prevent alcohol use among youth: a literature review. Santé Publique. 2013; S1(HS1):37-45.

38. Kersaudy-Rahib D, Clément J, Lamboy B, Lydié N. Interventions validées ou prometteuses en prévention des grossesses non prévues : synthèse de la littérature, Evidence-based and promising interventions to prevent unplanned pregnancies: a literature review. Santé Publique. 2013;S1(HS1): 25-35.

39. Lamboy B, Clément J, Saïas T, Guillemont J. Interventions validées en prévention et promotion de la santé mentale auprès des jeunes. Santé Publique. 2012;23(HS):113-25.

40. Lamboy B, Clément J, Saïas T, Guillemont J. Interventions validées en prévention et promotion de la santé mentale auprès des jeunes, Evidencebased interventions in youth mental health prevention and promotion. Santé Publique. 2011;23(HS):113-25.

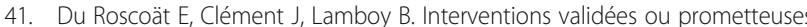
en prévention de la consommation de substances illicites chez les jeunes: synthèse de la littérature. Santé Publique 2013. (HS1), 47-56. https://doi.org/ 10.3917/spub.130.0047

42. Perry M, Becerra F, Kavanagh J, Serre A, Vargas E, Becerril V. Communitybased interventions for improving maternal health and for reducing maternal health inequalities in high-income countries: a systematic map of research. Glob Health. 2015;10:63.

43. Bennett C, Underdown A, Barlow J. Massage for promoting mental and physical health in typically developing infants under the age of six months. Cochrane Database of Syst Rev 2013, Issue 4. Art. No.: CD005038. https://doi.org/10.1002/14651858.CD005038.pub3.

44. Miller S, Maguire LK, Macdonald G. Home-based child development interventions for preschool children from socially disadvantaged families. Cochrane Database of Syst Rev 2011, Issue 12. Art. No.: CD008131. https://doi.org/10.1002/14651858.CD008131.pub2.

45. Gilmer C, Buchan JL, Letourneau N, Bennett CT, Shanker SG, Fenwick A, et al. Parent education interventions designed to support the transition to parenthood: a realist review. Int J Nurs Stud. 2016;59:118-33.

46. Halford WK, Petch J. Couple psychoeducation for new parents: observed and potential effects on parenting. Clin Child Fam Psychol Rev. 2010;13(2): 164-80.

47. Mcdaid D, Park A-L. Investing in mental health and well-being: findings from the DataPrev project. Health Promot Int. 2011;26(Suppl 1):1108-39.

48. Barlow J, Bergman H, Kornør H, Wei Y, Bennett C. Group-based parent training programmes for improving emotional and behavioural adjustment in young children. Cochrane Database of Syst Rev 2016, Issue 8. Art. No. CD003680. https://doi.org/10.1002/14651858.CD003680.pub3.

49. Welsh J, Strazdins L, Ford L, Friel S, O'Rourke K, Carbone S, et al. Promoting equity in the mental wellbeing of children and young people: a scoping review. Health Promot Int. 2015;30(Suppl 2):ii36-76.
50. Geens N, Vandenbroeck M. The (ab)sense of a concept of social support in parenting research: a social work perspective. CHILD Fam Soc WORK. 2014; 19(4):491-500.

51. Piotrowski CC, Talavera GA, Mayer JA. Healthy steps: a systematic review of a preventive practice-based model of pediatric care. J Dev Behav Pediatr JDBP. 2009;30(1):91-103.

52. Marmot M. Fair Society, Healthy Lives - The Marmot review. Strategic Review of Health Inequalities in England post-2010. Available from: http:// www.instituteofhealthequity.org/resources-reports/fair-society-healthy-livesthe-marmot-review/fair-society-healthy-lives-full-report-pdf.pdf.

53. Marmot M, Allen J, Goldblatt P. A social movement, based on evidence, to reduce inequalities in health. Soc Sci Med. 2010;71:1254-8.

54. de Parseval GD. L'art d'accommoder les bébés. Paris: Odile Jacob; 2001. p. 318.

55. Bronfenbrenner U. Ecology of the family as a context for human development: research perspectives. Dev Psychol. 1986;22(6):723-42.

56. Hawe P, Shiell A, Riley T. Theorising interventions as events in systems. Am J Community Psychol. 2009:43(3-4):267-76.

57. Moore GF, Audrey S, Barker M, Bond L, Bonell C, Hardeman W, et al. Process evaluation of complex interventions: Medical Research Council guidance. BMJ. 2015;350:h1258.

58. Whiting P, Savović J, Higgins JPT, Caldwell DM, Reeves BC, Shea B, et al. ROBIS: a new tool to assess risk of bias in systematic reviews was developed. J Clin Epidemiol. 2016;69:225-34.

\section{Ready to submit your research? Choose BMC and benefit from:}

- fast, convenient online submission

- thorough peer review by experienced researchers in your field

- rapid publication on acceptance

- support for research data, including large and complex data types

- gold Open Access which fosters wider collaboration and increased citations

- maximum visibility for your research: over $100 \mathrm{M}$ website views per year

At BMC, research is always in progress.

Learn more biomedcentral.com/submissions 